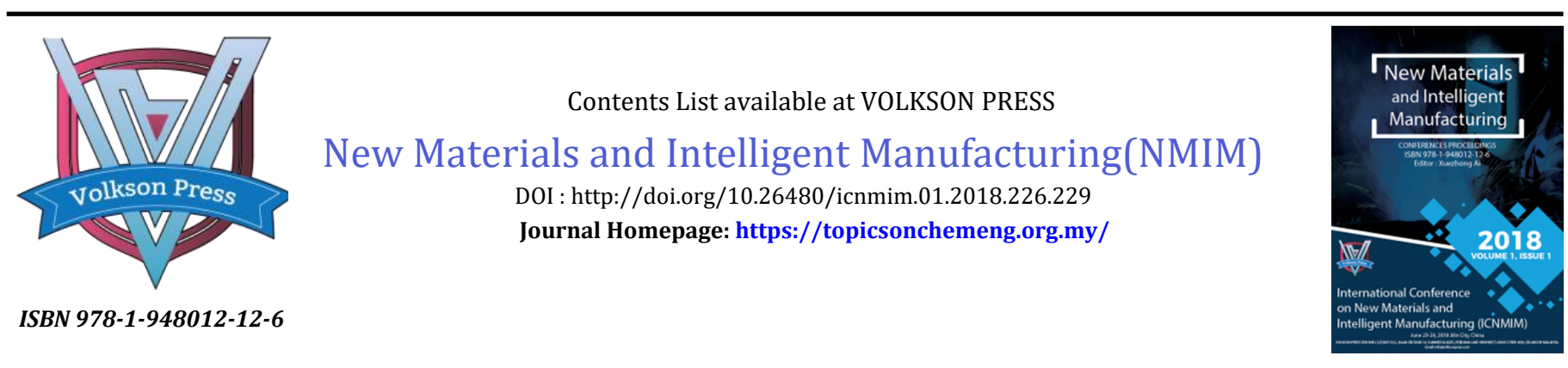

\title{
EFFECT OF FABRICATION PARAMETERS AND MATERIAL FEATURES ON DIMENSIONAL ACCURACY OF FDM BUILD PARTS
}

\author{
Zhenhui Shen ${ }^{1 *}$, Haiyan Hua ${ }^{2}$, Shuanqiang Yang1, Yangmei Zhang ${ }^{1}$ \\ ${ }^{1}$ Engineering College, Fujian Jiangxia University, University Town, Fuzhou, P.R.China \\ ${ }^{2}$ School of Mechanical and Automotive Engineering, Fujian University of Technology, University Town, Fuzhou, P.R.China \\ *Corresponding Author Email: shenzhenhui@fjixu.edu.cn
}

This is an open access article distributed under the Creative Commons Attribution License, which permits unrestricted use, distribution, and reproduction in any medium, provided the original work is properly cited

\section{ARTICLE DETAILS}

\section{Article History:}

Received 26 June 2018 Accepted 2 july 2018

Available online 1 August 2018

\section{ABSTRACT}

This paper presents experimental investigations on influence of fabrication parameters viz., layer resolution, processing quality, fill mode and the processing material on dimensional accuracy of fused deposition modelling (FDM). The test specimen is designed and the levels of each factor are setup. Then Taguchi's parameter design is applied to find optimum parameters setting to minimize percentage change in direction of X, Y and $\mathrm{Z}$ of test specimen. As the percentages changes are obtained, the signal to noise ratio is defined to evaluate the influence and variation. Then main effect plot is drawn to find optimal level of fabrication parameters. The results indicate that optimal factor settings for each performance characteristic are different. Therefore, analysis of variance is performed to calculate the significance level of experiment factors affecting to the dimensional accuracy in each direction. Finally, the effect of fabrication parameters and material features on dimensional accuracy of FDM build parts is obtained.

\section{KEYWORDS}

Fused Deposition Modelling, Dimensional Accuracy, Taguchi's Parameter Design, Main Effect Plot, Analysis of Variance

\section{INTRODUCTION}

With the development of computer technology and the application of new material, additive manufacturing which commonly known as 3D printing has been used widely across the world due to its short productive cycle, and will surely play a more and more important part in people's lives [1]. According to 3D printing, 3D solid models are fabricated from CAD data automatically without special tools or moulds. As a result, 3D printing has serval advantages especially in its ability to produce products with complex structure compared to traditional subtractive manufacturing [2]. The 3D printing includes technologies like fused deposition modeling (FDM), selective laser sintering (SLS), stereolithography apparatus (SLA), laminated object manufacturing (LOM), and so on. The FDM melts the filamentous material with the nozzle and makes the object by deposit the hot-melt materials, and features simple mechanical structure, easily operation and low material cost. As a result, the FDM developed rapidly and becomes the most popular technology. Nevertheless, it has been proposed that improvement of surface quality, part strength, build time, accuracy and repeatability are key issues to be addressed for successful implementation of 3D printing [3]. Several attempts have been made to carried out the effects of factors like data processing, build orientation, machine structure, fabrication parameters, material features on properties of 3D build parts [4,5]. However, the existing researches consider low number of factors and all the processes proceeding with different equipment have their own relative merits and demerits.

Therefore, the fabrication parameters and materials are selected and Taguchi's parameter design is applied to understand process parameters and their effects on response like dimensional accuracy of FDM build parts in this paper.

\section{EXPERIMENTAL SETUPS}

The UP Plus 2 produced by Beijing Tiertime Technology Co. Ltd is used as FDM printing equipment. The build volume is $140 \times 140 \times 135 \mathrm{~mm}$ and the filament diameter is $1.75 \mathrm{~mm}$. The fabrication parameters of the equipment include processing quality, layer resolution, fill mode, sealing surface setting, support setting, extruder temperature, platform temperature. The equipment can fabricate parts with extruded materials like ABS, ABS+, PLA, conductive and more.

A test specimen is designed to measure the dimensional accuracy of the FDM build parts and the detail drawing of which is shown in figure 1 . Considering the support will surely reduce the quality of the bottom surface and result in great measurement errors, the test specimen is constructed with a pedestal. The nominal dimension of $\mathrm{X}, \mathrm{Y}$ and $\mathrm{Z}$ of the body are set to $10 \mathrm{~mm}$. 3D solid model of the test specimen is built in Pro/Engineer 5.0 software and exported as STL file.

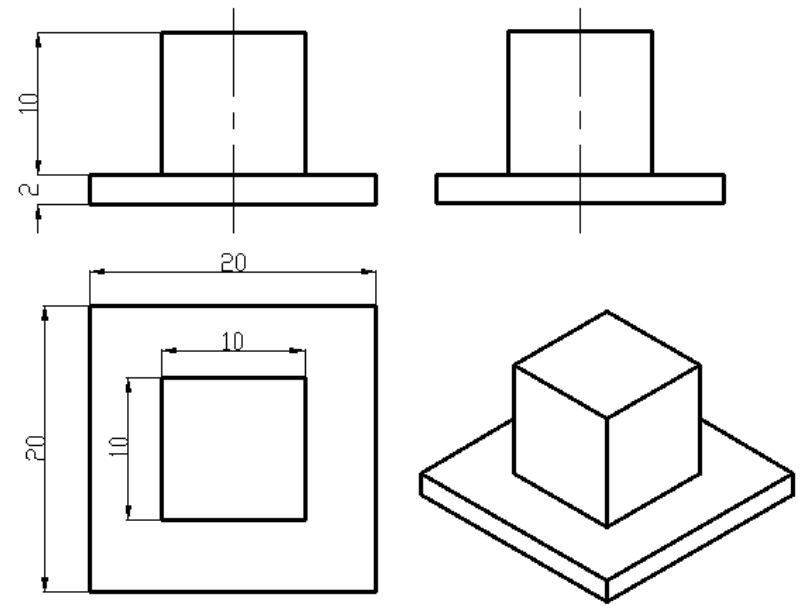

Figure 1: Detail drawing of test specime 
Considering not all the factors has a great effect on dimension accuracy of FDM build parts, the fabrication parameters like processing quality, layer resolution, fill mode and the processing material set to ABS or PLA are selected as the affecting factors in the experiment. Then the other fabrication parameters are set to defaults, which are value the same during the FDM printing of experiments besides the adaptation extruder temperature set by equipment system according to the processing material. Moreover, the affecting factors include layer resolution, processing quality, fill mode and the processing material are considered as factor A, B, C and D, respectively. And the values of each factors in the experiment are shown in Table 1 . The processing quality as well as fill mode values 3 levels while the layer resolution values 6 levels.

Table 1: Values of each factors

\begin{tabular}{|lllll|}
\hline $\begin{array}{l}\text { Factors } \\
\text { Levels }\end{array}$ & A & B & C & D \\
\hline 1 & $0.15 \mathrm{~mm}$ & fast & $\begin{array}{l}\text { Completely } \\
\text { Filled }\end{array}$ & PLA \\
2 & $0.20 \mathrm{~mm}$ & normal & $\begin{array}{l}\text { Incompletely } \\
\text { Filled }\end{array}$ & ABS \\
3 & $0.25 \mathrm{~mm}$ & fine & Shell & \\
4 & $0.30 \mathrm{~mm}$ & & & \\
5 & $0.35 \mathrm{~mm}$ & & & \\
6 & $0.40 \mathrm{~mm}$ & & & \\
\hline
\end{tabular}

After that, an experiment plan is designed based on orthogonal test design (OTD) with mixed levels according to Taguchi's parameter design. The OTD can not only improve the uniformity of factors' value during tests, but also reduce the test time which referring to experiment time cost. The number of tests in designed experiment plan is 27 and expressed by $N$. Each test in experiment is operated $n$ times and $n$ is set to 5. The FDM printing of test specimen and the axes of the FMD printing equipment is shown in Figure 2.

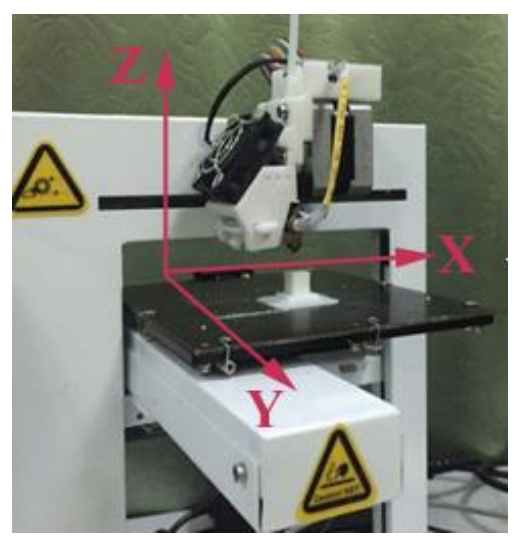

Figure 2: The FDM printing of test specimen

\section{RESULT ANALYSIS AND DISCUSSION}

Three readings of $X, Y$ and $Z$ are taken per sample and percentage change in dimension is calculated by

$$
\Delta D_{i}=\frac{\left|D_{i}-D_{\mathrm{O}}\right|}{D_{\mathrm{O}}} \times 100
$$

where $D_{i}$ represents the measurement value of $X$ or $Y$ or $Z$ while $i$ is the operation index of each test and valued $1 \sim n$. $D_{0}$ represents the nominal dimension of the test specimen and $\Delta D_{i}$ stands for percentage change in $D_{i}$. According to Taguchi's parameter design, signal to noise $(\mathrm{S} / \mathrm{N})$ ratio is applied to evaluate the influence and variation caused by each factor to the total variation observed in the result. Since the objective of experiment plan is to reduce the percentage change in $X, Y$ and $Z$, smaller the better quality characteristic is considered. Consequently, $\mathrm{S} / \mathrm{N}$ ratio expressed as $\eta$ can be determined by $\eta=-10 \log _{10}\left(\sum_{i=1}^{n} \Delta D_{i}^{2} / n\right)$

Experimental data on percentage change in dimensions of each test is convert to $\mathrm{S} / \mathrm{N}$ ratio and shown in Table 2. The range of $\mathrm{S} / \mathrm{N}$ ratio is [13.74,12.64] for $\Delta X,[-9.92,7.96]$ for $\Delta Y,[-4.78,13.98]$ for $\Delta Z$. Main effect plot for $\mathrm{S} / \mathrm{N}$ ratio shown in Figure 3 is used to predict optimum factor level with significant factors. The results indicate that optimal factor settings for each direction of the FDM build part are different. According to main effect plot, the optimum factor levels for $\Delta X, \Delta Y, \Delta Z$ are $\mathrm{A}_{1} \mathrm{~B}_{3} \mathrm{C}_{1} \mathrm{D}_{2}, \mathrm{~A}_{1} \mathrm{~B}_{3} \mathrm{C}_{1} \mathrm{D}_{1}$ and $\mathrm{A}_{4} \mathrm{~B}_{3} \mathrm{C}_{1} \mathrm{D}_{1}$, respectively. Table 2 shows the delta values stand for response of ratio. The values show that the influence of the factors follows the sequence as $\mathrm{B}>\mathrm{A}>\mathrm{C}>\mathrm{D}$ for $\Delta X, \mathrm{~A}>\mathrm{B}>\mathrm{C}>\mathrm{D}$ for $\Delta Y, \mathrm{~A}>\mathrm{B}>\mathrm{C}>\mathrm{D}$ for $\Delta Z$. And then the relative influence of each factor is determined by analysis of variance (ANOVA). Parameters of ANVOA like degree of freedom (DOF), sum of square deviation (SS), mean square (MS), F-ratio (F) and p-value (P) is calculated and shown in table $3-5$. As the significance level is set to 0.05 , it is considered that the factor has obvious influence on the dimensional accuracy when $\mathrm{P}<0.05$ and vice versa. It is observed that significant factors are $\mathrm{A}$ and $\mathrm{B}$ for $\Delta X$, B for $\Delta Y, \mathrm{~A}, \mathrm{~B}$ and $\mathrm{C}$ for $\Delta Z$.

Table 1: $\mathrm{S} / \mathrm{N}$ ratio of percentage change in experiment plan

\begin{tabular}{|c|c|c|c|c|c|c|c|}
\hline \multirow{2}{*}{ Exp. No. } & \multicolumn{4}{|c|}{ Factors } & \multicolumn{3}{|c|}{$\mathrm{S} / \mathrm{N}$ ratio } \\
\hline & A & B & $\mathrm{C}$ & D & $\% \Delta X$ & $\% \Delta Y$ & $\% \Delta Z$ \\
\hline 1 & 1 & 1 & 1 & 1 & -1.82 & 0.29 & 1.24 \\
\hline 2 & 1 & 1 & 2 & 1 & -0.56 & 2.31 & 0.60 \\
\hline 3 & 1 & 2 & 1 & 2 & 4.44 & 0.29 & 1.94 \\
\hline 4 & 1 & 2 & 3 & 1 & 5.46 & 3.52 & -1.58 \\
\hline 5 & 1 & 3 & 2 & 2 & 11.48 & 3.52 & 2.69 \\
\hline 6 & 1 & 3 & 3 & 1 & 12.64 & 6.02 & 1.24 \\
\hline 7 & 2 & 1 & 2 & 1 & -6.58 & -2.28 & -2.50 \\
\hline 8 & 2 & 1 & 3 & 1 & -6.02 & -1.82 & -2.92 \\
\hline 9 & 2 & 2 & 1 & 1 & 4.44 & 0.00 & 1.94 \\
\hline 10 & 2 & 2 & 2 & 2 & 4.44 & 0.92 & 3.52 \\
\hline 11 & 2 & 3 & 1 & 1 & 7.26 & 7.96 & 4.44 \\
\hline 12 & 2 & 3 & 3 & 2 & 7.96 & 0.00 & 2.69 \\
\hline 13 & 3 & 1 & 1 & 1 & -11.05 & -5.11 & -0.56 \\
\hline 14 & 3 & 1 & 3 & 1 & -8.30 & -7.60 & 0.00 \\
\hline 15 & 3 & 2 & 2 & 1 & -2.28 & -0.83 & 0.60 \\
\hline 16 & 3 & 2 & 3 & 2 & -4.94 & 0.00 & 1.94 \\
\hline 17 & 3 & 3 & 1 & 2 & 9.54 & -0.28 & 2.69 \\
\hline 18 & 3 & 3 & 2 & 1 & 6.62 & 7.26 & 6.62 \\
\hline 19 & 4 & 1 & 3 & 2 & -11.13 & -7.36 & 1.24 \\
\hline 20 & 4 & 2 & 2 & 1 & -8.94 & -3.90 & 5.46 \\
\hline 21 & 4 & 3 & 1 & 1 & -1.34 & 6.02 & 13.98 \\
\hline 22 & 5 & 1 & 1 & 2 & -2.05 & 1.58 & -1.09 \\
\hline 23 & 5 & 2 & 3 & 1 & -9.45 & -4.78 & -2.05 \\
\hline 24 & 5 & 3 & 2 & 1 & 8.71 & 1.58 & 0.00 \\
\hline 25 & 6 & 1 & 2 & 2 & -13.74 & -9.92 & -4.78 \\
\hline 26 & 6 & 2 & 1 & 1 & 0.92 & -7.60 & -0.56 \\
\hline 27 & 6 & 3 & 3 & 1 & -3.52 & 3.52 & -1.58 \\
\hline
\end{tabular}



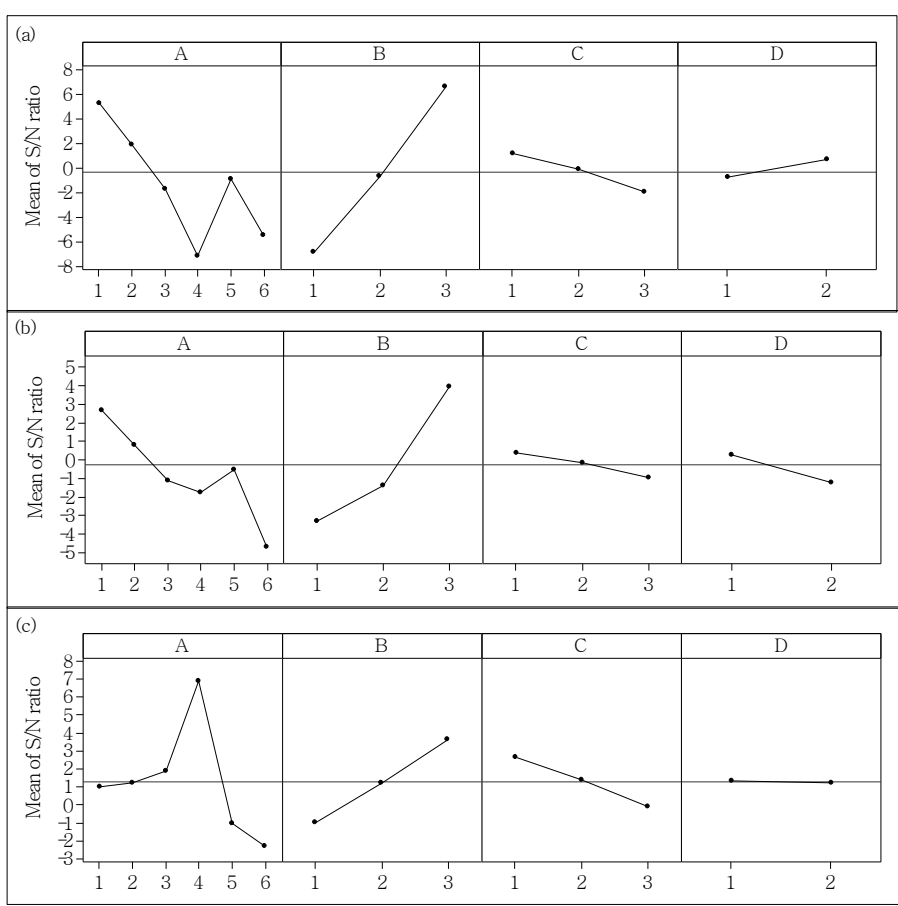

Figure 3: Main effect plot (a) $\Delta \mathrm{X}$, (b) $\Delta \mathrm{Y}$ and (c) $\Delta \mathrm{Z}$ for $\mathrm{S} / \mathrm{N}$ ratio

Table 3: Response of $\mathrm{S} / \mathrm{N}$ ratio

\begin{tabular}{|c|c|c|c|}
\hline \multirow{2}{*}{ Factor } & \multicolumn{3}{|l|}{ Delta } \\
\hline & $X$ & $Y$ & $Z$ \\
\hline A & 12.4087 & 7.3277 & 9.2014 \\
\hline B & 13.40135 & 7.2789 & 4.6154 \\
\hline $\mathrm{C}$ & 3.07035 & 1.2951 & 2.7829 \\
\hline D & 1.43243 & 1.504 & 0.1466 \\
\hline
\end{tabular}

Table 4: ANOVA table for $\mathrm{S} / \mathrm{N}$ ratio of $\Delta \mathrm{X}$

\begin{tabular}{|llllll|}
\hline Source & DOF & SS & MS & F & P \\
\hline A & 5 & 449.08 & 89.82 & 7.35 & 0.001 \\
B & 2 & 810.02 & 405.01 & 33.13 & 0 \\
C & 2 & 42.93 & 21.47 & 1.76 & 0.204 \\
D & 1 & 12.31 & 12.31 & 1.01 & 0.331 \\
Error & 16 & 195.63 & 12.23 & & \\
Total & 26 & 1509.97 & & & \\
\hline
\end{tabular}

Table 5: ANOVA table for $\mathrm{S} / \mathrm{N}$ ratio of $\Delta \mathrm{Y}$

\begin{tabular}{|llllll|}
\hline Source & DOF & SS & MS & F & P \\
\hline A & 5 & 127.145 & 25.429 & 2.35 & 0.088 \\
B & 2 & 255.598 & 127.799 & 11.81 & 0.001 \\
C & 2 & 7.68 & 3.84 & 0.35 & 0.707 \\
D & 1 & 13.573 & 13.573 & 1.25 & 0.279 \\
Error & 16 & 173.109 & 10.819 & & \\
Total & 26 & 577.105 & & & \\
\hline
\end{tabular}

Table 6: ANOVA table for $\mathrm{S} / \mathrm{N}$ ratio of $\Delta \mathrm{Z}$

\begin{tabular}{|llllll|}
\hline Source & DOF & SS & MS & F & P \\
\hline A & 5 & 152.002 & 30.4004 & 8.2 & 0.001 \\
B & 2 & 95.909 & 47.9545 & 12.93 & 0 \\
C & 2 & 34.89 & 17.4448 & 4.7 & 0.025 \\
D & 1 & 0.129 & 0.129 & 0.03 & 0.854 \\
Error & 16 & 59.339 & 3.7087 & & \\
Total & 26 & 342.269 & & & \\
\hline
\end{tabular}

Therefore, based on the above analysis, the significant factors and levels of dimensional accuracy vary form direction of FDM build parts. Factor of layer resolution mainly influences $\Delta X$ and $\Delta Z$, and it affects $\Delta Y$ with significance level on 0.10 . Factor of processing quality influences all direction of the FDM build parts at a significance level. Factor of fill mode have great influence on $\Delta Z$ and little influence on $\Delta X$ and $\Delta Y$. Factor of processing material had no prominent influence on dimensional accuracy of FDM build parts.

\section{CONCLUSION}

In the present work, effect of four factors of fabrication parameters viz., layer resolution, processing quality, fill mode and the processing material with different levels is studied on the dimensional accuracy of FDM build parts. Taguchi's design of experiment is applied to find the significance of factors. The main effect plot for $\mathrm{S} / \mathrm{N}$ ratio is obtained and ANOVA is performed for $\mathrm{S} / \mathrm{N}$ ratio. It is found that the optimum factor levels for $\Delta X$, $\Delta Y, \Delta Z$ are $\mathrm{A}_{1} \mathrm{~B}_{3} \mathrm{C}_{1} \mathrm{D}_{2}, \mathrm{~A}_{1} \mathrm{~B}_{3} \mathrm{C}_{1} \mathrm{D}_{1}$ and $\mathrm{A}_{4} \mathrm{~B}_{3} \mathrm{C}_{1} \mathrm{D}_{1}$, respectively. Furthermore, factor of layer resolution mainly influences the dimensional accuracy on the direction of $X$ and $Z$. Factor of processing quality influences the dimensional accuracy on all direction of the FDM build parts. Factor of fill mode have great influence the dimensional accuracy on the direction of $Z$. And factor of processing material had no prominent influence on dimensional accuracy on all direction of the FDM build parts. In future, the proposed methodology may be tested for studying influence on mechanical properties of FDM build parts and make a greater contribution to optimum fabrication parameters for FDM build parts with complex structure.

\section{ACKNOWLEDGMENTS}

This work is supported by the Education Scientific Research Project for the Young Teacher of Fujian Province, China (Grant No. JAT170613), the Natural Science Foundation of Fujian Province, China (Grant No. 2016J01727) and the Scientific Research Foundation Project of Fujian University of Technology, China (Grant No. GY-Z14075).

\section{REFERENCES}

[1] Berman, B. 2012. 3-D printing: the new industrial revolution. Business Horizons, 55 (2), 155-162. doi: 10.1016/j.bushor.2011.11.003

[2] Kariz, M., Sernek, M., Obućina, M., Kuzman, M.K. 2017. Effect of wood content in FDM filament on properties of 3D printed parts. Materials Today Communications, 14, 135-140. doi: 10.1016/j.mtcomm.2017.12.016

[3] Kaveh, M., Badrossamay, M., Foroozmehr, E., Etefagh, A.H. 2015. Optimization of the printing parameters affecting dimensional accuracy and internal cavity for HIPS material used in fused deposition modeling processes. Journal of Materials Processing Tech, 226, 280-286. doi: 10.1016/j.jmatprotec.2015.07.012

[4] Min, K.K., Lee, I.H., Kim, H.C. 2018. Effect of fabrication parameters on surface roughness of FDM parts. International Journal of Precision Engineering \& Manufacturing, 19 (1), 137-142. doi: 10.1007/s12541-0180016-0

[5] Sharma, R., Singh, R., Penna, R., Fraternali, F. 2018. Investigations for mechanical properties of hap, pvc and pp based 3D porous structures obtained through biocompatible FDM filaments. Composites Part B Engineering, 132, 237-243. doi: 10.1016/j.compositesb.2017.08.021 


\section{ABOUT THE AUTHORS}

Zhenhui Shen received his master's degree in 2011 for Fuzhou University. Now, he is a Lecturer in Engineering College, Fujian Jiangxia University. His main research directions include intelligent and automatic system, intelligence optimize design.

Haiyan Hua received her PhD degree in 2014 for Fuzhou University. Now, she is a Lecturer in School of Mechanical and Automotive Engineering, Fujian University of Technology. Her main research directions include intelligent and automatic system, intelligence optimize design.
Shuanqiang Yang received his PhD degree in 2016 for Fuzhou University. Now, he is an Associate Professor in Engineering College, Fujian Jiangxia University. His main research directions include intelligent and automatic system.

Yangmei Zhang received her master's degree in 2014 for Fuzhou University. Now, she is a Experimentalist in Engineering College, Fujian Jiangxia University. Her main research directions include intelligent and automatic system, intelligence optimize design. 